\title{
A NEUROSE OBSESSIVA SOB A ÓTICA DE MELANIE KLEIN*
}

Marcos Leandro Klipan e Gustavo Adolfo Ramos Mello Neto

Marcos Leandro Klipan Psicólogo clínico, mestre em Psicologia pela Universidade Estadual de Maringá.

Gustavo Adolfo Ramos Mello Neto Professor doutor do Departamento de Psicologia (Universidade Estadual de Maringá), doutor em Psicologia (USP).
RESUMO: Essa pesquisa aborda o tema 'neurose obsessiva' na obra de Melanie Klein. Assim, foi possível estudar um panorama histórico da construção do pensamento dessa autora — tendo em vista que seguimos um itinerário cronológico de seus textos - e, como consequência importante, obter uma dimensão epistemológica dessa construção. Isso porque a neurose obsessiva constitui-se como um destacado elemento organizador da obra de Klein, sobretudo nas décadas de 1920 e 1930, período que marcou o atendimento dos primeiros pacientes da autora que, em sua maioria, eram crianças que sofriam de neurose obsessiva.

Palavras-chave: Melanie Klein, neurose obsessiva, sadismo, reparação, posição depressiva.

ABSTRACT: The obsessive neurosis from Melanie Klein's optic. This research focuses on obsessive neurosis in Melanie Klein's. Thus, it was also possible to study a historical broad view of the construction of this author's thought, having in mind that a chronological itinerary was followed, and, as an important consequence, an epistemological dimension of this construction was obtained. This was so because the obsessive neurosis constitutes an outstanding organizing element in Klein's work, mainly in the 1920's and 30's. This time was marked by the observation of the author's first patients, who were, in their majority, children suffering from obsessive neurosis.

Keywords: Melanie Klein, obsessive neurosis, sadism, reparation, depressive position.

\footnotetext{
* Trabalho financiado pela Capes/DS.
} 
0 que se propõe aqui é examinar o tema neurose obsessiva na obra de Melanie Klein. Essa ideia inspira-se em uma dissertação de mestrado (KLIPAN, 2009) e num projeto de ensino e pesquisa intitulado "Laboratório de Estudos em Psicanálise”, da Universidade Estadual de Maringá (PR). Foi, então, no contexto desse último que ela surgiu, tendo em vista que esta pesquisa se desenvolveu como subprojeto de um projeto maior, que se baseou nesse Laboratório e foi chamado de "O discurso psicanalítico sobre a neurose obsessiva depois de Freud".

A pesquisa buscou estudar a neurose obsessiva e mostrar como se desenrolava o 'fio' da história do pensamento psicanalítico em torno de um objeto fixo - no caso, a neurose obsessiva. Isso já havia sido feito antes pelo mesmo grupo, mas tendo por base a histeria, e o que se encontrou foi a psicanálise discutindo, revendo e recriando os seus próprios conceitos na medida que observava a histeria passar por mutações através dos tempos. Isso de tal maneira que os autores se perguntavam se era a histeria ou a psicanálise que havia mudado nesses 70 anos.

A neurose obsessiva, de algum modo, foi a co-star da histeria no surgimento da psicanálise. Note-se que em um texto de Freud ainda tão inicial e tão fundador (“As neuropsicoses de defesa”, de 1894), ambas as neuroses já estão lá, como objetos privilegiados da teorização psicanalítica. É desse modo que, um século inteiro passado, pareceu valer a pena ver como o pensamento psicanalítico se 'comporta' frente a esses dois quadros. Feito, pois, o trabalho em torno da histeria, o que se propôs, então, foi o mesmo em relação à neurose obsessiva.

Buscou-se, assim, referências e resumos de textos psicanalíticos por meio do PsycInfo, a base bibliográfica da Associação Americana de Psicologia, o maior indexador mundial na área psi. Realizada a leitura desses resumos, procedeu-se a uma classificação temática. Dentre os temas encontrados estava a "neurose obsessiva no pensamento de autores clássicos”. Resolveu-se privilegiar Melanie Klein e Lacan, os dois principais carros-chefes da psicanálise de hoje, sem menosprezar outras linhas e autores. O presente trabalho constitui-se, portanto, a partir dessa temática e em torno da escolha da obra de Melanie Klein como contexto para a discussão da neurose obsessiva.

A ideia que desenvolvemos aqui é de que o tema 'neurose obsessiva' esteve como cenário e personagem na formulação e na posterior transformação das teorias de Klein, isto é, das ideias que estão nos primeiros escritos e depois aparecem em A psicanálise de crianças (1932/1997), e nas construções teóricas subsequentes, que enfatizam as formulações a respeito do mecanismo chamado 'reparação', bem como na teoria sobre as 'posições'. 
O começo: a criação de uma técnica psicanalítica de crianças e as primeiras considerações teóricas

O que talvez seja a primeira menção feita por Klein à neurose obsessiva pode ser encontrada no artigo “A análise de crianças pequenas”, de 1923. Ali, a autora procurou esboçar seus primeiros achados — talvez ainda não inteiramente psicanalíticos - e a compreender a constituição de muitas inibições, especialmente as escolares, em seus pequenos pacientes. Ao discorrer sobre o interjogo de forças presentes na inibição, a autora rediscute o ‘caso’ Leonardo, de Freud.

Apesar de manter muitos apontamentos de Freud (1910/1996) em relação às inibições do gênio da Renascença - como, por exemplo, o intenso interjogo inconsciente, fantasístico e sexual, que seria expresso pela fantasia/lembrança de Da Vinci sendo tocado pela cauda de um abutre em seu berço - a autora procurou destacar o intenso sadismo na dinâmica psíquica das crianças desde sua mais tenra idade. Para isso, ressaltou dois elementos propostos por Freud que foram, depois, muito importantes para suas formulações teóricas e conceituais. Referimo-nos à noção metapsicológica de "pulsão epistemofílica”1 (Wisstrieb) e sua conexão com o sadismo. Tal ideia, de certa forma, já aparecia em Freud quando buscava desmistificar a existência de um “idílio bem-aventurado” (FREUD, 1910/1996, p.131) suposto pelos adultos acerca do universo infantil. Com Klein, essa desmistificação toma o colorido especial de suas descrições das fantasias inconscientes infantis, que acabaram revelando que o universo psíquico inicial da criança é algo 'infernal'.

A neurose obsessiva aparece em "A análise de crianças pequenas", e o faz em negativo. Aparece justamente quando a autora afirma que é muito provável que Da Vinci tenha conseguido escapar de uma estruturação obsessiva, pelo fato de ter uma capacidade sublimatória tão ou mais intensa que seu sadismo — surgido concomitantemente à pulsão epistemofílica. Para Klein, o intenso desejo de saber sobre as coisas à sua volta, derivava de um violento desejo de conhecer 0 corpo da mãe e ser reconhecido por esta. Da Vinci era impulsionado a conhecer o mundo e a natureza, tal como a criança busca conhecer o corpo da mãe, em especial o seu interior. Essa observação de Klein tentou mostrar que esse desejo era intensamente atravessado pelo sadismo que derivava de frustrações iniciais sentidas pela criança (desmame e treino ao toalete) e, também, da impossibilidade de compreensão da criança das coisas que aconteciam à sua volta.

Segundo a autora (1923/1996), por se tratar de um momento em que o ego é muito incipiente, esse sadismo seria mais intensamente sentido, o que poderia

\footnotetext{
${ }^{1}$ Essa ideia é primeiramente proposta por Freud em "Notas sobre um caso de neurose obsessiva" (1909/1996), ou o "Homem dos ratos”, como ficou conhecido. Ocorrem poucas menções posteriores de Freud a este termo que, muitas vezes, foi traduzido para o português como 'instinto de conhecimento' ou 'instinto de saber'.
} 
trazer marcas posteriores, como as inibições intelectuais nas crianças em sua fase de aprendizagem — uma neurose.

A pulsão epistemofílica seria, então, a interação entre as forças sexuais e agressivas (sádicas). Nos casos bem-sucedidos dessa interação, a pulsão epistemofílica levaria o sujeito ao encontro com o outro e com o mundo, numa relação de crescimento egoico.

Klein (1923/1996) procura mostrar que o obsessivo teria esses impulsos (o sexual, o agressivo e/ou epistemofílico) precocemente estimulados. Sua futura atitude mentalmente "ruminante" (suas obsessões) seria uma marca dessa precocidade.

No entanto, a origem dessa precocidade sexual representada pela pulsão epistemofílica do obsessivo não é tão clara nesses primeiros textos de Klein. Há algum aprofundamento do tema nas relações apontadas entre mãe e filha no caso da pequena Erna, discutido em A psicanálise de crianças, que veremos adiante. Ali, faremos uma discussão dessa origem a partir da teoria da sedução generalizada de Jean Laplanche (1992).

Mas, antes de chegarmos à década de 1930, podemos encontrar elementos parecidos e que se relacionam a uma cena essencialmente marcada no pensamento teórico dessa autora: a cena primitiva. Aqui, referimo-nos ao artigo "Contribuição à psicogênese dos tiques”, de 1925, em que Klein analisou o universo fantasístico do garoto Felix, que sofria de tiques e tinha um caráter - muito mais do que sintomas - obsessivo.

Nesse artigo, Klein buscou destacar que as representações lúdicas do menino - e das crianças de um modo geral — eram, no fundo, representações da relação sexual fantasiada pela criança derivadas da cena primária. O exemplo clínico de Felix é bastante ilustrativo a esse respeito, pois o menino apresentava, segundo a autora, toda uma fantasia que circulava ao redor dos sons ouvidos por ele, quando ainda era bem pequeno, e que vinham da cama dos seus pais. Klein interpretou esse elemento sonoro como um dos componentes da cena primária e que foi responsável, mais tarde, pelo intenso interesse do menino pela música, contraposto pela posterior inibição em relação a ela e à arte em geral - a inibição teria surgido quando do retorno do pai de Felix da guerra e a reprimenda que esse dirigiu ao garoto por se interessar tanto por essas coisas (subentendidas como femininas), ao invés de se interessar por esportes. O menino, então, atendeu exatamente a esse pedido do pai, mas passou a sofrer de severos tiques e inibição escolar.

Isso, de algum modo, colocaria em discussão o que diz Freud em “A disposição à neurose obsessiva” (1913/1996). Trata-se de certa precocidade do desenvolvimento do ego em relação ao desenvolvimento da pulsão. Diz esse autor: 
“sugiro a possibilidade que uma ultrapassagem cronológica do desenvolvimento libidinal pelo desenvolvimento do ego deve ser incluída na disposição à neurose obsessiva. Uma precocidade deste tipo tornaria necessária a escolha de um objeto sob a influência dos instintos do ego, numa época em que os instintos sexuais ainda não assumiram sua forma final”. (FREUD, 1913/1996, p.348)

Nesse contexto, Klein, mais uma vez, salienta como o universo do obsessivo era intensamente sexualizado (cena primária e a sedução que daí se deriva) ${ }^{2}$ e, também, muito agressivo. Essa agressividade, no caso de Felix, apareceu, por exemplo, quando estava em um teatro ouvindo um concerto e ficou bastante irritado com o desempenho do maestro da orquestra. Klein interpretou essa cena como o menino estando irritado com a potência sexual do pai. Uma irritação e um desdém agressivos deslocados do pai para o maestro, que assumiu, nas fantasias de Felix, a figura de um pai impotente.

Dessa forma, Klein busca mostrar a existência de uma constante e intensa interação entre o sexual e o agressivo, não se tratando, pois, apenas de um grau de polaridade. ${ }^{3}$ E todo esse sadismo derivado das fantasias agressivas das crianças traria um resultado pesado para elas, um forte sentimento de culpa já experimentado desde a mais tenra idade.

Isso levou Klein a perceber a atuação do superego num momento muito anterior àquele proposto pela psicanálise de então. O superego se formaria, pois, antes do declínio do complexo edipiano. Na verdade, Klein começa a postular que esse complexo se instauraria a partir das primeiras construções superegoicas - derivadas diretamente da atividade agressiva no psiquismo das crianças pequenas. Estas seriam, então, uma espécie de retorno de toda a agressividade projetada pela criança num funcionamento parecido com a lei de talião: a agressividade retornaria em ataques sádicos contra ela mesma. O superego da criança, em especial o das obsessivas, seria tão sádico quanto suas tendências agressivas.

A autora organiza melhor este ponto em um texto do ano seguinte, "Princípios psicológicos de crianças pequenas”, de 1926 — já bem próximo à proposta de $A$ psicanálise de crianças, tendo dado origem ao primeiro capítulo desse livro.

\footnotetext{
${ }^{2}$ Podemos pensar na exigência do pai de Felix como uma sedução desse tipo.

${ }^{3}$ Klein almejava explicitar essa interação entre as pulsões sexuais e agressivas como duas forças muito próximas que estariam, muitas vezes, mescladas em certas fantasias. Era seu desejo que a compreensão da atividade psíquica que derivava dessas forças inconscientes não se tratasse, apenas, de polos antagônicos na gênese do conflito psíquico.
} 
Ainda em 1926, Klein apresenta, pela primeira vez, dois de seus principais casos de neurose obsessiva: a pequena Rita ${ }^{4}$ e o já citado caso Erna. ${ }^{5}$ Nessa primeira menção, ambos os casos foram pouco detalhados no que se referia ao cotidiano das crianças, diferentemente do que vai ocorrer em A psicanálise de crianças. Todavia, os elementos sádicos que Klein queria evidenciar no universo psíquico dessas crianças já aparecem bem destacados nesses casos, o que nos remete diretamente à neurose obsessiva.

A autora aponta que, nas crianças da mais tenra idade, o sadismo derivado de suas primeiras frustrações causava intensa angústia. Aí, pode-se dizer que ela já começa a propor, de forma mais explícita e mais bem teorizada, o surgimento do complexo de Édipo na criança num período bem mais precoce do que o pensado por Freud. Isso porque Klein observava, em crianças bastante pequenas como Rita, que apresentavam um interjogo de desejos amorosos e hostis típicos do complexo de Édipo. E mais: apresentavam, segundo a autora (1926/1996), um sentimento de culpa tão peculiar quanto aquele que só poderia ser derivado do superego. Ficava assim proposto que não só o complexo de Édipo era mais precoce do que se havia pensado, mas que, também, não aparecia apenas em seu término, e sim ao mesmo tempo. Tratava-se, no entanto, de um superego mais primitivo.

Pela dimensão da tese que deriva desses dois casos de neurose obsessiva, percebemos que foram os mais revisitados pela autora. A cada revisão, Klein abordava-os com detalhes mais profundos sobre as fantasias inconscientes dessas crianças, o que revelava aspectos cada vez mais arcaicos do psiquismo.

Citamos como exemplo o caso Erna. Em 1926, as angústias sentidas por essa pequena paciente, e que constituíam sua neurose obsessiva, foram apontadas por Klein como caracteristicamente anais. Em A psicanálise de crianças essa característica anal foi colocada em segundo plano, tendo em vista que o elemento oral - e a correspondente inveja que começava a aparecer associada a essa oralidade passou a ganhar destaque nessas angústias primitivas.

Ao final da década de 1920, Klein publicou dois textos que aprofundariam o desenvolvimento de suas ideias acerca das angústias infantis e do complexo

\footnotetext{
${ }^{4}$ Rita era uma menina de 2 anos e nove meses na época do atendimento e que sofria com um severo cerimonial obsessivo e terrores noturnos que a atormentavam, assim como a seus pais, porque a obrigavam a cumprir uma série de condições antes de dormir, tais como ser bem apertada na cama para evitar ser mordida em seus órgãos genitais, ou ter sempre consigo o elefante de pelúcia - uma exigência imperiosa - para evitar que ele tentasse ir ao quarto dos seus pais. Trata-se de uma clara projeção de seus desejos libidinais e agressivos, como Klein demonstrou, projetados no brinquedo.

${ }^{5}$ Erna era uma criança de 6 anos, que desde muito cedo mostrava diversos sintomas obsessivos. Além de ser muito severa consigo mesma em suas fantasias inconscientes, evidenciando um superego extremamente sádico, tinha atitude e interesse sexuais precoces.
} 
de Édipo primitivo: Estágios iniciais do complexo edipiano (1928/1996) e Personificação no brincar das crianças (1929/1996). O primeiro não faz apontamentos novos e diretos sobre a neurose obsessiva, mas é um texto importante por conter uma das teses principais da autora - como enunciado no próprio título - e tem a neurose obsessiva como uma das protagonistas na formulação de seu roteiro.

Já o segundo texto desenvolve importantes apontamentos em relação à compreensão da autora sobre qual seria a função e o significado do brincar para a criança. Aí, Klein afirma que a capacidade de brincar implica pôr em ação fantasias que serão personificadas no decurso do jogo. A inibição, derivada da angústia e do sentimento de culpa que estão no palco do sadismo das fantasias infantis, impediria esse processo. Seguindo essa linha de raciocínio, a autora percebe que, quanto maior a inibição na brincadeira, maiores seriam os sentimentos de culpa decorrentes do sadismo. O grau de inibição no brincar e na personificação dos jogos infantis passou a ser critério de avaliação da gravidade do caso e seu diagnóstico, segundo Klein. Quanto maior a inibição, maior a severidade da patologia. A neurose obsessiva se mostrava, então, como um dos casos graves dessa patologia.

Ainda nesse texto (1929/1996), Klein faz um apontamento novo sobre essa patologia e suas características. Diz-nos que é bastante comum que traços isolados de características obsessivas componham o desenvolvimento 'normal' das crianças.

\section{A PSICANÁLISE DE CRIANÇAS: EM BUSCA DE UMA SISTEMATIZAÇÃO}

Em A psicanálise de crianças, podemos pensar num alinhavo no fio condutor que fizemos da neurose obsessiva em relação à obra de Melanie Klein, além, evidentemente, da sistematização que aí encontramos, tanto em relação à teoria, quanto da técnica relacionada à psicanálise de crianças. Isso porque a autora retoma aí pontos que já havia destacado em relação a essa patologia, além de ampliar outros.

Klein retoma certos pontos trazendo novos detalhes, como, por exemplo, com relação ao caso Erna. Ao discutir esse caso, ao longo das páginas do terceiro capítulo de A psicanálise de crianças (1932/1997), apresenta-nos uma Erna com detalhes mais lascivos do que nas "versões" anteriores. Esse aspecto sexual, junto com a dimensão paranoide que a autora buscou frisar sobre o mundo interno da menina, nos faz retomar aquela ideia de 1923 sobre o violento desejo de conhecer e ser reconhecida pela mãe. Erna, ao ser intensamente frustrada em suas primeiras fontes de prazer - a oral e a anal — tornou-se uma criança ambivalente e curiosa em relação à sua mãe desde muito cedo. A autora nos conta como a mãe se sentia 'sugada' (1932/1997) pela necessidade de Erna estar constantemente junto a ela. 
Nesse ponto, Klein percebeu que Erna havia reagido muito mal às frustrações do desmame e do treino ao banheiro, apesar de ter sido aparentemente bem educada durante esse período e apresentar uma aceitação externa bastante dócil.

Em seu universo de fantasias, contudo, a criança personificava sua brincadeira com tonalidades bem agressivas e persecutórias. Isso se alternava com elementos de uma sedução que, por sua vez, traziam a ela, quase instantaneamente, extrema culpa e angústia. Erna construiu, em suas brincadeiras, uma figura feminina bastante sedutora e agressiva. Todavia, por muito tempo, como nos diz Klein, apesar de tais figuras serem terrificantes em sua fantasia, Erna não as associava ou fazia ligações dessas fantasias com sua mãe real. A menina nunca fazia, por exemplo, acusações ou reclames contra a figura real. Erna tratava desse seu imaginário, em princípio, exclusivamente no plano das representações lúdicas.

Além desse novo detalhe sobre a relação entre Erna e sua mãe, outro se destaca na retomada do caso pela autora: a mãe de Erna notou que a menina, quando bebê, parecia sentir enorme prazer ao ser limpa em seus genitais e, por isso, houve a necessidade de maior discrição nessa higiene. Klein (1932) associa essa sedução sentida por Erna à forma lasciva pela qual se apresentava frente aos meninos, ou mesmo homens, fazendo com que parecesse uma adolescente sedutora, apesar dos seus 6 anos de idade.

Essa forma de cuidado descrita por Klein, sentido por Erna como sedução, remeteu-nos à ideia freudiana da pulsão epistemofílica, quando relacionada ao neurótico obsessivo: a de que esse sujeito teria experimentado um interesse sexual muito precoce. Klein nos aponta justamente esse caminho quando dá detalhes sobre esse universo cotidiano da relação mãe-filha no caso Erna. No entanto, não se aprofunda nesse plano, digamos, da sedução adulto-criança. Laplanche (1992) é quem nos oferece maiores elementos teóricos para compreendermos que, nessa relação, a criança é seduzida pelo adulto, e aqui não se trata de algo pedófilo, mas de uma instauração sexual necessária. Isso ocorre não apenas pelos toques corporais, como apontado nessa relação descrita por Klein (1932/1997), mas, principalmente, por mensagens enigmáticas do adulto que atingem a criança. Enigmáticas para a criança e, também, para o adulto, pois são mensagens inconscientes. Sobre isso, pensamos que essa teoria de Laplanche (1992) pode ser uma via interessante para pensar por que, no obsessivo, esse toque foi sentido como precocemente sedutor. A resposta não estaria apenas no toque, mas em todo o enigma inconsciente contido nele.

É algo, portanto, enigmático e sexual. Tal como o enigma da esfinge, lançado a Édipo na tragédia de Sófocles: decifra-me ou te devoro. Esfinge que nessa tragédia, significativamente, é colocada às portas de Tebas, como num início, o que podemos comparar ao início do psiquismo, com todos os seus enigmas por serem decifrados em um mundo ameaçador, como nos revela Klein. 
Todavia, a autora não faz esse tipo de leitura. Mesmo assim, percebe que essa tragédia inicial da criança precisa ser, a duras penas, superada. A neurose obsessiva — não como patologia apenas, mas como recurso ou função — aparece aí como uma tentativa extrema de evitar a derrocada psíquica representada pela psicose.

Sobre isso, Klein destaca a integração psíquica e faz importantes discussões referentes às dúvidas típicas do neurótico obsessivo. E isso a autora sistematiza no oitavo e nono capítulos de $A$ psicanálise de crianças. A(s) dúvida(s) típica(s) do neurótico obsessivo se basearia(m), segundo a autora (1932/1997), em uma dúvida original em ter ou não estragado o corpo da mãe e, também, numa busca obsessiva de tentar restaurar os danos causados nesse interior. Mais tarde, essa dúvida recairia sobre o plano intelectual, tal como afirma a autora. Mas tudo se iniciaria naquela sedução, por exemplo, do toque que, para o obsessivo, marcaria a origem de sua precocidade sexual. Aqui nos encontramos diante da construção do mecanismo que Klein chamou de reparação.

Assim, um sentimento persecutório seria típico da neurose obsessiva e também da paranoia, como Klein buscou apontar na análise da pequena Erna. A tentativa de reparação desse estrago fantasisticamente causado, surgiria como um avanço na integração do ego e de seus objetos internos (integração). Mudarse-ia de tipo psicótico de angústia ${ }^{6}$ para uma forma mais neurótica desse afeto, que seriam o pesar e a culpa, consistindo em reconhecer o objeto como um todo e perceber os sentimentos ambivalentes em relação a ele. Nessa tentativa de restaurar o objeto estragado pelos ataques sádicos, a criança que faz um uso saturado desse mecanismo de características obsessivas (reparação), pois não suportaria a culpa por ter atacado esse objeto amado. Assim, realiza uma 'eterna' tentativa de repará-lo.

Com isso, a neurose obsessiva, segundo Klein (1932/1997), é apontada como um dos últimos recursos utilizados pela criança contra sua condição inicial de característica psicótica e afetivamente persecutória. Klein chamou de mecanismos obsessivos essa tentativa de restaurar o dano no interior do corpo da mãe que, no fundo, seria um reflexo do dano realizado no próprio psiquismo da criança, em função do seu sadismo. Tanto as crianças neuróticas como as "normais” fariam uso desse mecanismo. A diferença estaria no uso saturado de tal mecanismo nos sujeitos neuróticos obsessivos, que teriam menos recursos simbólicos e sublimatórios como, por exemplo, a limitada personificação no brincar das crianças obsessivas. Isso seria, pois, um limite entre a neurose obsessiva e a psicose, que

\footnotetext{
${ }^{6}$ Principalmente a partir de A psicanálise de crianças, Melanie Klein começa a diferenciar, de maneira enfática, dois tipos de angústia: uma de característica psicótica, mais primitiva e representando um psiquismo menos integrado, e outra mais neurótica - em termos de estrutura — que depois passa a ser relacionada à concepção de posição (posição depressiva).
} 
Abraham (1916/1970) havia destacado antes. Para Klein (1932/1997), esse limite estaria, sobretudo, nesse tipo de mecanismo de defesa que lutaria contra a culpa derivada do reconhecimento da mãe como um todo e da dependência dela.

O neurótico obsessivo, ao final de A psicanálise de crianças (1932/1997), pode ser compreendido como um trágico sujeito que sofre por pendular entre duas grandes ameaças: a primeira, representada pela perseguição que ainda deriva de seu estado caótico inicial - que depois foi chamado de posição esquizoparanoide. A segunda, concebida pela angústia em reconhecer o objeto como um todo.

Seguindo esse fio condutor a partir do tema neurose obsessiva, percebemos que, à medida que a autora avançava em sua compreensão sobre esses mecanismos obsessivos, a psicose começava a assumir o papel de protagonista na cena de suas teorias; e não por acaso, tendo em vista que esse próprio mecanismo, revelava um modo bastante primitivo de funcionamento psíquico.

Estabelece-se, então, uma nova fase no trabalho de Klein. E o que mais a define como nova é a inauguração do conceito de posição, cuja ênfase substitui aquela dada às fases psicossexuais. Tal proposta teria o sentido de evidenciar o dinamismo psíquico que a autora percebia ao investigar os mecanismos de defesa e suas angústias predominantes. O artigo que inaugurou esse período foi “Uma contribuição à psicogênese dos estados maníaco-depressivos”, de 1935. Vamos a ele, rapidamente.

\section{UMA MENTE PRIMITIVA EM DESTAQUE}

Em “Uma contribuição à psicogênese dos estados maníaco-depressivos”, de 1935, o mecanismo de reparação já aparece bastante ligado ao conceito de posição, principalmente no que tange à sua função organizadora e integradora do psiquismo. A neurose obsessiva reaparece, aí, muito próxima aos apontamentos feitos pela autora em A psicanálise de crianças, em especial quanto ao modo de funcionamento obsessivo que, segundo Klein (1935/1996), seria um dos recursos que o ego, em formação, utilizaria em seus momentos mais arcaicos. Haveria, então, uma constante projeção dos perseguidores internos, derivados do sadismo.

A autora mostra ainda esse modo de funcionamento obsessivo também presente nas psicoses maníaco-depressivas. Tal como Abraham (1916/1970) havia percebido semelhanças na ambivalência em relação ao objeto de amor por parte do obsessivo e do depressivo, Klein afirma que em ambos haveria uma tentativa desesperada de manter intacto esse objeto. O maníaco-depressivo, ao seu modo tendo em vista que acredita que seu objeto já esteja perdido - também buscaria no mecanismo obsessivo de reparação uma salvaguarda contra suas angústias persecutórias (paranoides). Nos casos de neuróticos graves (casos fronteiriços) observados por Klein (1935/1996), tanto adultos quanto crianças, haveria uma 
mistura de tendências paranoicas e depressivas nesses pacientes. Ou seja, aquela linha divisória proposta por Abraham (1916/1970; 1924/1970) entre a psicose e a neurose, que mostrava uma proximidade entre a paranoia e a neurose obsessiva, passou a ser entendida como mais tênue e bastante oscilante em suas fundações, tal como a teoria das posições começava a sugerir.

Ainda nesse texto de 1935, Klein propõe as três principais defesas do período de integração egoica da posição depressiva que, como se sabe, são a negação, a idealização e a onipotência no que tange ao reconhecimento integral do objeto, mas, sobretudo, naquilo que diz respeito ao reconhecimento da própria dependência em relação a ele. Esta dependência é sentida como perigosa, tal como a autora aponta, depois, em $\mathrm{O}$ luto e suas relações com os estados maníaco-depressivos, de 1940, texto considerado uma continuação de Uma contribuição à psicogênese dos estados maníaco-depressivos.

Nesse artigo de 1940, não há menção à neurose obsessiva, mas um importante apontamento que supomos ser derivado das considerações sobre ela surge como um dos postulados da posição depressiva. Diz Klein: “[...] De acordo com minha experiência, a preocupação e o pesar em torno da perda tão temida dos objetos 'bons' — ou seja, a posição depressiva — é a fonte mais profunda dos dolorosos conflitos que ocorrem na situação edipiana [...]” (1940/1996, p.388). Essa primitiva experiência de perda seria revivida em todas as perdas posteriores do sujeito, em especial naquelas relacionadas ao luto, tal como a autora teoriza nesse artigo. Dessa forma, é possível supor que a vivência e a elaboração da posição depressiva podem ser entendidas como um primeiro organizador da dor da perda e, sobretudo, das angústias primitivas relacionadas a esse período. Quanto mais intensa a vivência — e as consequentes revivescências — dessa dor da perda original, mais intensas e primitivas seriam as defesas contra essa angústia.

Baranger (1976) indica-nos, pois, que seria a qualidade da angústia (psicótica ou neurótica) e as decorrentes defesas psíquicas que norteiam Klein, e mais tarde as escolas kleinianas, em seus diagnósticos.

A posição depressiva seria "uma melancolia em status nascendi" (KLEIN, 1940/1996, p.388) que necessita ser superada para a ascensão a uma modalidade neurótica de funcionamento psíquico. Essa última passa, então, a ser vista como um padrão de "normalidade" vivida pelas crianças até o seu período de latência. Segundo a autora, que o sustenta desde A psicanálise de crianças (1932/1997), a neurose seria um meio normal de trabalhar e modificar as angústias de tipo psicótico que o bebê enfrentaria nos seus meses iniciais de vida. Parece ainda segura ao mencionar, em uma nota de rodapé (1940/1996), constatação semelhante à que Freud fizera em 1926, em A questão da análise leiga: conversações com uma pessoa imparcial: a de que a neurose na criança seria regra, e não exceção. Vai além do que propôs em 1932, ao dizer que a concepção da posição depressiva fez com 
que percebesse que esta é “[...] a posição central no desenvolvimento da criança” (KLEIN, 1940/1996, p.390).

Essa seria uma neurose "normal” e transitória, tendo em vista que seria superada após a resolução edipiana; se diferenciaria da patológica pela intensidade e modo de funcionamento das defesas psíquicas, o que inclui aqui a reparação, que é uma defesa de tipo obsessivo.

Assim, uma das características mais arcaicas que podemos encontrar na neurose obsessiva, e que não se restringe apenas ao seu quadro psicopatológico, refere-se ao mecanismo de reparação que surge na posição depressiva como uma tentativa do ego de enfrentar as angústias depressivas e sua inerente culpa. Em determinada situação, quando, por exemplo, o ego não consegue vencer a ansiedade depressiva e esta se torna persecutória, em função do sadismo (KLEIN, 1940/1996), ele pode utilizar de forma obsessiva o mecanismo de reparação em sua tentativa de restaurar o objeto amado atacado. Klein chama esse tipo de defesa de maníacas ou de posição maníaca, por sua relação com a doença maníacodepressiva (idem).

Em 1946, em Notas sobre alguns mecanismos esquizoides, Klein cunha o conceito posição esquizoparanoide. E, principalmente, a partir daí abre um grande leque para as investigações acerca de elementos mais primitivos da mente, em especial sobre o que se refere à psicose. Nesse texto, pouca coisa aparece de novo em relação aos elementos da neurose obsessiva. Todavia, cabe destacar o controle obsessivo que surgiria nas projeções intensas ocorridas no psiquismo primitivo. A autora começa a teorizar sobre partes do self que seriam projetadas nesse primitivo mecanismo de defesa. Isso abriu espaço para a construção do conceito de identificação projetiva — que não abordaremos aqui. Podemos, contudo, destacar que haveria uma tentativa obsessiva de controle nessas projeções primitivas, tal como nos indica a autora. Eis, pois, uma característica obsessiva que Klein percebeu na cena dessa dinâmica primitiva:

“ [...] O impulso de controlar outras pessoas é, como sabemos, um elemento essencial na neurose obsessiva. A necessidade de controlar outras pessoas pode até certo ponto ser explicada por um impulso defletido de controlar partes do self. Quando essas partes foram excessivamente projetadas para dentro de uma outra pessoa, elas só podem ser controladas através do controlar a outra pessoa. Uma raiz dos mecanismos obsessivos pode, então, ser encontrada no tipo particular de identificação que advém dos processos projetivos infantis. Essa conexão pode também lançar alguma luz sobre o elemento obsessivo que tantas vezes entra na tendência à reparação. Pois o sujeito é levado a reparar ou restaurar não apenas um objeto em relação ao qual ele vivencia a culpa, mas também a reparar ou restaurar partes do self.” (KLEIN, 1946/1997, p.32, grifos nossos) 
Partes do self, e não apenas do ego, como a autora teorizava antes, que estariam em jogo no contexto tido como um dos mais — se não o mais — primitivos do psiquismo, o atinente à inveja derivada das frustrações orais. Essa discussão é feita por Klein em Inveja e gratidão (1957/1997). Aqui se trata de uma inveja voraz que buscaria estragar o seio da mãe, palco mais arcaico que começa a ser visto como primeiro cenário das atividades fantasísticas da criança, ao invés do interior do corpo, que passa a ser subentendido como algo mais integrado.

Klein fala ainda de uma tentativa de estragar a criatividade da mãe, o que seria sentido como um estado bastante confuso e caótico para a criança. Sobre esse aspecto, supomos não ser absurdo propor uma ligação com aquela dúvida obsessiva que vimos e que diz respeito aos danos supostamente realizados no interior do corpo da mãe. No caso específico de Inveja e gratidão, o seio passa a ser o novo (ou o mais antigo) cenário da construção dos enigmas originais do ser humano, naquele sentido utilizado por Laplanche (1992). Diz Klein: “O seio bom que nutre e inicia a relação de amor com a mãe é o representante da pulsão de vida e é também sentido como a primeira manifestação da criatividade" (KLEIN, 1957/1997, p.233).

E essa percepção faz aparecer uma cobiça, no bebê, em relação a essa “onipotência” da mãe. Algo que Klein identifica como a raiz da criatividade e que, quando demasiadamente invejado pelo bebê, o impulsiona à destruição daquilo que é sentido por ele como o dom maior da mãe: a sua capacidade de gerar a vida. Nesse sentido, Klein nos fala dos ataques que as crianças pequenas promovem, em suas fantasias inconscientes, contra os bebês que as mães teriam em seu interior — há um desejo agressivo de roubá-los e destruí-los. Assim, esses ataques contra a criatividade da mãe levariam a criança ao medo de ser perseguida por seu próprio sadismo projetado. O bebê começaria a desconfiar, ou duvidar, de seu objeto de satisfação, que passaria a ser visto como estragado - o seio "mau", como Klein fala em outros momentos.

A integração egoica e psíquica (self) fica, assim, caracterizada como a necessária superação dos ódios e invejas iniciais. Uma primazia do amor sobre os sentimentos destrutivos.

Depois disso, a neurose obsessiva não aparece mais neste e nos textos subsequentes, mas ficou marcada como um dos últimos recursos para a superação das condições psicóticas iniciais. Um recurso que se engessaria devido ao uso saturado da reparação, essencial, mas que fica imobilizada em função do sadismo não mitigado (pulsão de morte).

Desta forma, relembramos ao leitor que o que procuramos, aqui, foi indicar como o estudo da neurose obsessiva foi um dos principais caminhos que permitiu a Melanie Klein estabelecer suas ideias sobre a posição depressiva e um de seus principais mecanismos de defesa, a reparação. Algo parecido ocorrera com Freud 
em relação à histeria, ao criar seu conceito de recalcamento. A neurose obsessiva, na obra de Klein, não se restringiu apenas ao seu aspecto psicopatológico; ganhou, também, um status de modalidade de funcionamento psíquico, tal como podemos ver na construção da posição depressiva quando, em determinado momento, foi chamada de posição obsessiva (KLEIN, 1935/1996).

Recebido em 7/12/2009. Aprovado em 21/6/2010.

\section{REFERÊNCIAS}

ABRAHAM, K. (1970) Teoria psicanalítica da libido: sobre o caráter e o desenvolvimento da libido. Rio de Janeiro: Imago.

(1911) “Notas sobre as investigações e o tratamento psicoanalítico da psicose maníaco-depressiva e estados afins”, p.32-50.

(1916) “O primeiro estágio pré-genital da libido”, p.51-80.

(1924) "Breve estudo do desenvolvimento da libido, visto à luz das perturbações mentais", p. 81-160.

BARANGER, W. (1976) Posición y objeto en la obra de Melanie Klein. Buenos Aires: Kargieman.

GROSSKURTH, P. (1992) O mundo e a obra de Melanie Klein. Rio de Janeiro: Imago.

FREUD, S. (1996) Edição standard brasileira das obras psicológicas completas de Signund Freud. Rio de Janeiro: Imago.

(1984) “As neuropsicoses de defesa”, v.III, p.51-77.

(1907) "Notas sobre um caso de neurose obsessiva”, v.IX, p.105117.

(1909) “Atos obsessivos e práticas religiosas”, v.X, p.137-215.

(1910) “Leonardo Da Vinci e uma lembrança de sua infância”, v.XI, p.67-141.

(1913) “A disposição à neurose obsessiva”, v.XII, p.337-349.

(1926) “A questão da análise leiga: conversações com uma pessoa imparcial", v.XX, p.175-248.

KLEIN, M. (1996) Obras completas de Melanie Klein. Rio de Janeiro: Imago.

(1923) “A análise de crianças pequenas”, v.I, p.100-128.

(1925) “Uma contribuição à psicogênese dos tiques”. (André Cardoso, Trad.) v.I, p.129-151).

(1926) "Princípios psicológicos da análise de crianças pequenas", v.I, p.152-163.

(1928) “Estágios iniciais do complexo de edipiano”, v.I, p.214-227.

(1929) “Personificação no brincar das crianças”, v.I, p.228-239.

(1935) “Uma contribuição à psicogênese dos estados maníacodepressivo”, v.I, p.301-329. 
(1940) "O luto e suas relações com os estados maníaco-depressivos", v.I, p.385-412.

KLEIN, M. (1997) Obras completas de Melanie Klein. Rio de Janeiro: Imago.

(1932) “A psicanálise de crianças”, v. II, p. 1-350.

KLEIN, M. (2006) Obras completas de Melanie Klein. Rio de Janeiro: Imago.

(1946) "Notas sobre alguns mecanismos esquizoides", v.III, p.1743.

(1957) “Inveja e gratidão”, v.III, p.205-267.

KLIPAN, M. (2009) “A neurose obsessiva sob a óptica de Melanie Klein”.

Programa de Pós-Graduação em Psicologia, Universidade Estadual de Maringá (PR).

LAPLANCHE, J. (1992) Novos fundamentos para a psicanálise. São Paulo: Martins Fontes.

Marcos Leandro Klipan

mklipan@yahoo.com.br

Gustavo Adolfo Ramos Mello Neto

garmneto@hotmail.com 